\title{
Stage Unspecified
}

National Cancer Institute

\section{Source}

National Cancer Institute. Stage Unspecified. NCI Thesaurus. Code C28066.

The extent of cancer involvement is not stated. 